\title{
Acute pneumonia - a theme we should all be studying
}

\author{
Otelo S. Ferreira, ${ }^{1}$ Murilo C.A. Britto ${ }^{2}$
}

\begin{abstract}
The learned study by Sarria et al. which goes into the diagnosis of acute pneumonia (AP), in the current issue of our ever improving Jornal de Pediatria, is most welcome. ${ }^{1}$ This is a subject in which even the most experienced professionals should be constantly updating themselves.

While the scientific fundamentals of AP have not changed for decades, current epidemiological data and the dynamics of the theme itself, which is proper to medicine, stimulate us all to read with attention when this theme is the subject.
\end{abstract}

Around $10-20 \%$ of all children under five in poor countries present AP every year. ${ }^{2}$ In 1995, of the 11.6 million deaths of under-fives, 4 million were due to AP, making it the most common cause of death. Ninety-five percent of these deaths occurred in poor countries and $50-75 \%$ of the victims were less than a year old. 2,3

In Brazil, in 1998, 5.4\% and $12.8 \%$ of deaths among children less than one year old and from one to four years old respectively were caused by PA. ${ }^{3}$ The most recent statistics tell us that acute respiratory infections (ARI) are the second or third greatest cause of death among underfives, in these regions and that $85 \%$ of deaths due to ARI are from PA. ${ }^{2,3}$ In 1999, in Brazil, 8.1\% of hospitalizations, at all ages, were caused by AP. In those under five, this figure reached $26.7 \% .{ }^{3}$ In the Americas, ARI are the cause of 20 $40 \%$ of all hospitalizations of under-fives. ${ }^{3}$

Acute pneumonia is a cause of death which can be averted by simple measures that are accessible, of low cost and do not usually require sophisticated diagnostic technology or therapeutic resources. ${ }^{3,4}$ It is the condition for which most can be done to reduce infant mortality and deaths of those under five. ${ }^{4,5}$ Other than in exceptional cases, diagnostic delay or error is involved in AP deaths. And, as a rule, rich children do not die of AP. Doctors should be ever aware of this.

The search for refined diagnoses, particularly of whether AP is viral or bacterial, remains important. There are many

1. MSc. Centro de Ciências da Saúde, Universidade Federal de Pernambuco (CCS/UFPE), Recife, PE, Brazil.

2. PhD. Instituto Materno Infantil de Pernambuco (IMIP), Recife, PE, Brazil. recent publications on the theme, such as that by Virkki et al. ${ }^{6}$ They showed that $71 \%$ of their patients with alveolar infiltration had a probable bacterial infection. There were, therefore, $29 \%$ of cases that exhibited this radiological pattern without any bacterial origin being found. On the other hand, they found that $72 \%$ of those presumed to have bacterial disease did have alveolar infiltration. Thus, $28 \%$ of the cases with a bacterial disease profile did not present infiltration. Also, half of those with an interstitial infiltration radiological pattern had a profile suggestive of bacterial disease. In $49 \%$ of the patients with just a viral infection there were alveolar abnormalities, and in $15 \%$ of these it was lobar. In the experience of these authors leukocyte and C-reactive protein counts were not of use in separating viral from bacterial

disease. $^{6}$

Little progress has been achieved to resolve the diagnostic dilemma and to define more precise treatment. Doctors continue to use the methods of thirty to forty years ago to define their conduct: "it is pneumonia according to clinical and radiological criteria" (tachypnea and others; lobar or segmental condensation, or multifocal and others) "and antibiotics should be prescribed". Or the condition is AP and "there is evidence that it is severe (malnutrition, cyanosis, dehydration, anemia, heart diseases, pneumopathy or other concurrent afflictions, the use of antibiotics and others) "and intervention should be more vigorous". It has been fully demonstrated that this is sufficient to reduce the high mortality rates still observed in poor countries.

The study by Sarria et al. is both relevant and original. It investigates interobserver variation, a polemic aspect of chest $\mathrm{x}$-rays for lower ARI diagnosis. With appropriate methodology and careful sample size calculation the authors note that the agreement between different observers leaves a lot to be desired for $\mathrm{PA}^{7}$ identification. Others have shown the same.

Certain aspects merit discussion. When assessing a diagnostic test it is imperative to have a gold standard. ${ }^{8}$ The authors used the clinical treatment prescribed as their reference standard, which is appropriate from an operational point of view. It is unlikely that this potential bias significantly influenced their results, but it should 
be taken into account. Another relevant factor is that, apart from the quality of the $\mathrm{x}$-rays themselves, the entire assessment was performed under ideal conditions, which makes the study appropriate to assess efficacy and not effectiveness. ${ }^{8}$ It can be further deduced that, under true working conditions, with time scarce and less wellqualified personnel, that interobserver variation would be greater still. As the group of children studied were all hospitalized, the external validity of this research is limited to more serious cases and cannot be extrapolated to cover outpatients treatment.

Nevertheless the study is a significant contribution to scientific research and to the understanding of this theme.

\section{References}

1. Sarria Icaza E, Fischer GB, Lima JAB, Menna Barreto SS, Flôres JAM, Sukiennik R. Concordância no diagnóstico radiológico das infecções respiratórias agudas baixas em crianças. J Pediatr (Rio J). 2003;79:497-503.
2. CDC. Division of Bacterial and Mycotic Diseases. Pneumonia among Children in Developing Countries. 2003; March 6: 2p.

3. Nascimento-Carvalho CM, Souza-Marques, H. Recomendação da Sociedade Brasileira de Pediatria para Antibioticoterapia de Crianças e Adolescentes com Pneumonia Comunitária. 2002; Julho: $8 \mathrm{p}$.

4. Filerman J, Chatkin JM, Chatkin M. Epidemiologia das infecções respiratórias agudas (IRAs). In: Silva LCC, Menezes AB. Epidemiologia das Doenças Respiratórias. Rio de Janeiro: Revinter; 2001. p. 90-103.

5. Sazawal S, Black RE. Meta-analysis of intervention trials on case-management of pneumonia in community settings. Lancet. 1992;340:528-33.

6. Virkki R, Rikalainen H, Sverdström E, Mertsola J, Ruuskanen O. Differentiation of bacterial and viral pneumonia in children. Thorax. 2002;57:438-41.

7. Schmidt MI, Duncan B. Epidemiologia clínica e a medicina embasada em evidências. In: Roquayrol Z. Epidemiologia e Saúde. Rio de Janeiro: Medsi; 1999. p. 183-206.

8. Cochrane AL. Effectiveness and efficiency. Random reflections on health services. Londres: BMJ Publishing Group; 1991. p. $1-103$.

\title{
The pediatrician and exclusive breastfeeding
}

\author{
Marina F. Rea*
}

$\mathbf{T}_{\mathrm{h}}$ duration in Brazil has been revealed in many studies and duration in Brazil has been revealed in many studies and reasons for this tendency has been offered. ${ }^{1}$ The most up to date data, from 1999, come from a study of state capitals performed by the Health Ministry, which confirmed the tendency and also made a diagnosis of what has been happening in terms of exclusive breastfeeding. ${ }^{2}$

The World Health Organization (WHO) proposed that children from birth to four months of age on exclusive breastfeeding (defined as just breastmilk, without even water or tea, allowing only vitamin drops) be used as the indicator, but this has not always proved comparable. The 1986 Demographic and Health Survey (DHS) statistics returned a prevalence of $3.6 \%$, while that in 1996 returned

* Public health physician. Professor, School of Medicine, Universidade Estadual de Campinas (UNICAMP), Campinas, SP, Brazil.
$40 \%$; this last was criticized for the manner in which data was collected because the questionnaire used did not permit that mothers who claimed to give only breastmilk be asked about the offer of water or tea. Consequentially, this figure is probably an overestimate. ${ }^{3}$

Even though this figure cannot be directly compared with that from 1986, it seems obvious that one can claim that between 1986 (less than 4\%) and 1996 (between $30 \%$ and $40 \%$ ) there was an increase in exclusive breastfeeding.

In terms of the value of this increase, we are still far from achieving the recommendation: that all children are exclusively breastfed until six months old. Nowadays both the WHO and national policy agree on the recommendation of exclusive breastfeeding for six months and on the continuation of breastfeeding, with the addition of complementary foods, from six months until at least two years. The proportion of children on exclusive breastfeeding at 180 days in the state capitals in 1999 was just $9.7 \%,{ }^{1}$ far 